\title{
Consumer Buying Behavior towards E-Commerce: A Survey Study of Consumers at a Selected Online Shopping Site in Dhaka, Bangladesh
}

\author{
Tanvir Abir ${ }^{1}$, Taha Husain ${ }^{2 *}$, Shaikh Sabbir Ahmed Waliullah"1, \\ Dewan Muhammad Nura Yazdani', Kazi Fayzus Salahin ${ }^{3}$, Md Adnan Rahman' \\ ${ }^{1}$ College of Business Administration-CBA, IUBAT-International University of Business Agriculture and Technology, Dhaka, \\ Bangladesh \\ ${ }^{2}$ Department of Gender and Development Studies, Begum Rokeya University, Rangpur, Bangladesh \\ ${ }^{3}$ Data Analyst and Communication Office, Eminence Associates or Social Development, Dhaka, Bangladesh \\ Email: tanvir.cba@iubat.edu, *ahmthusain@gmail.com, shaikh.waliullah@iubat.edu, dewanm@iubat.edu, \\ salahin@eminence-bd.org, adnan.cba@iubat.edu
}

How to cite this paper: Abir, T., Husain, T., Waliullah, S. S. A., Yazdani, D. M. N., Salahin, K. F., \& Rahman, M. A. (2020). Consumer Buying Behavior towards E-Commerce: A Survey Study of Consumers at a Selected Online Shopping Site in Dhaka, Bangladesh. Open Journal of Business and Management, $8,2716-2728$.

https://doi.org/10.4236/ojbm.2020.86168

Received: September 22, 2020

Accepted: November 22, 2020

Published: November 25, 2020

Copyright $\odot 2020$ by author(s) and Scientific Research Publishing Inc. This work is licensed under the Creative Commons Attribution International License (CC BY 4.0).

http://creativecommons.org/licenses/by/4.0/

\begin{abstract}
This study aims to evaluate the consumer's buying behaviours in online shopping sites in Bangladesh. This study follows a mixed-method approach where the researchers collected primary data from the questionnaire survey and in-depth interview of the customers who buy services from the e-commerce site. The findings from the cross-sectional study revealed positive effect $(P$-value $>0.005)$ of Psychographic Indicators (0.049); Economic Indicators (0.339); and Socio-cultural Indicators (0.297) coefficients on customer satisfaction towards e-commerce. However, the demographic factor is not statistically significant $(P$-value $>0.005)$ and does not put any impact (0.321) on customer satisfaction.
\end{abstract}

\section{Keywords}

Consumer Behavior, E-Commerce, Online Shopping, Technological Factors, User Satisfaction

\section{Introduction}

E-commerce involves the procurement of goods and services in an online platform by both the companies and consumers. To participate in e-commerce, potential customers need cell phones and access to the World Wide Web (Luck- 
ing-Reiley \& Spulber, 2001; Niranjanamurthy et al., 2013). Some scholars argued that the business utilization of the web is restricted because of the data transmission constraint (Parvin et al., 2007). There have also been some better shopping requirements, such as links to the platform, a fair loading time, clear product definition, reliability of purchases and efficiencies in navigation (Limayem et al., 2000).

Some research finds that visitor numbers are four times higher than the average visitor when the site uses local language (Dan, 2014). It was found that online shoppers are normally affluent, have better education, have a high degree of literacy in online activities, generally pass a lot of time using the computer and internet, and as a result, shopping through the internet has become more convenient and enjoyable for them and they feel less scared towards transactions in online platforms (Swinyard \& Smith, 2003). The decision-making mechanism for customers was defined as complicated with several factors influencing problem-recognition until a sequence of measures were undertaken to achieve an outcome (Erasmus et al., 2001).

Though it started in the late 1990s, E-commerce is still in the development process in Bangladesh (Abir et al. 2020; Hassan, 2014). Later in 2009, this industry started to expand when Bangladesh Bank inaugurated an online payment system for its Banking functionality. Bangladesh Bank also lifted its international payment restriction in 2013 and permitted payment for goods and services in online sites using debit and credit cards, thus promoting e-commerce business with the world market. In Bangladesh, Business to Customers (B2C) and web-based business is less rehearsed, but at the same time a very restrained level of Business to Government (B2G) and Business to Business (B2B) interchanges prevails (Jamil \& Ahmad, 2009). Like other growing countries, Bangladesh is reaping full advantages of developing internet business cost-effectiveness.

This country is also facing some barriers such as being suspicious about secure electronic exchange (Dey et al., 2009). Despite the fact, consumer's buying behaviour in Bangladesh has experienced a major change due to the improvement of people's living conditions and with the advancements of modern tech-based education. In Bangladesh, it is ascertained that due to low cost and availability to different products, on-site e-commerce becomes the most owing platform for buying items as the Internet becomes a wonderful place for online advertising to allure and acquire consumers (Rahman et al., 2018; Rowley, 2001; Mohiuddin, 2014; Lin, 2015; Laisuzzaman et al., 2010; Koyuncu \& Bhattacharya, 2004; Swinyard \& Smith, 2003; Dholakia \& Chiang, 2003; Shankar et al., 2003; Von et al., 2004; Laisuzzaman et al., 2010).

Additionally, this sector is becoming an eminent and fastest-growing sector in Bangladesh during the period of COVID-19 pandemic. There are approximately 2500 websites involved in the e-commerce industry and 150,000 e-commerce pages till 2018. Besides, at the retail level, the number of deliveries per day was 
around 15,000 to 20,000 (Sohrabi et al., 2020). As of February 2020, there were 166.114 million mobile subscriptions and 99.984 million internet subscribers in Bangladesh (BTRC, 2020). In Bangladesh, e-commerce business in the retail level has risen to $72 \%$ in recent time. Also, there are approximately 35,000 personal level retailers and 25,000 small and medium enterprise (SMEs) businesses actively participating in this market. As a developing country, there are several possibilities for Bangladesh to expand its business via the internet. Bangladesh's ICT service has taken on a wide range of activities to turn the web-based business industries into a new vibe such as getting installments via online transit point.

About ten thousand Facebook-commerce (f-commerce) businesses currently have their business in Bangladesh and 100 e-commerce companies are available outside of Facebook such as Chaldal.com; Meena Bazaar, Rokomari.com; Daraz BD; ajkerdeal.com; pickaboo.com; Othoba.com; and Bikroy.com (Karim \& Qi, 2018). Some foreign investors initiated e-commerce here as well such as; $O l x$, daraz, and kaymu. As the cost of server installation and purchasing of personal computers has declined over the years, the cloud-based market field is seeing an increased industry.

Bangladesh has recently become 42nd largest economy and in terms of purchasing power parity, this country posits 31 st in the world (The Financial Express, 2019). Not only that Bangladesh's per capita income is about to overturn that of India and the corresponding figure is seen growing to $\$ 1888$ (The Economic Times, 2020). Such economic growth in a country which has a large population (Worldometer, 2020) therefore creates an enormous opportunity for the e-commerce industry and e-commerce business. It would be a glorious opportunity to expedite all e-commerce dimensions including B2B, B2C, C2C and M-commerce (Chan, 2017). In this backdrop, the current segment of the study aims to identify factors influencing online buying in Bangladesh.

\section{Methodology}

\subsection{Research Methods and Sample}

This follows the quantitative research methodology. The primary data was collected from the customers' of Sheba.xyz (Sheba.xyz, 2016). By using a convenient sample, a survey was conducted and determined the desired sample by following the formula of Schlesselman (1974) “ $Z 2{ }^{*}(p) *(1-p) / C 2$ " where $Z=1.96$ for $95 \%$ confidence level, $p=0.5$ and $c=6.6 \%$. After applying the formula, the desired sample for the study was 220 . In this case, a structured survey questionnaire containing a series of questions was used. To do the data analysis a process of inspecting and cleansing were followed to refine the significant information and finally, the SPSS software was used for statistical analysis.

\subsection{Internal Consistency and Construct Validity}

The table above (Table 1) shows the matrix of correlations which demonstrates 
that all independent variables for this study have a value of less than 0.9 and they are all considered a separate structure.

First of all, for the three independent variables, the eta score proves that it has a medium association (0.4 to 0.69 ) with the dependent variable. And the eta squared value proves that psychographic indicators; economic indicators; socio-cultural indicators have $36 \%, 35 \%$ and $46 \%$ effect respectively on the dependent variable (customer satisfaction). Although the effects were highly statistically significant we usually notice this pattern with larger sample sizes (Table 2).

\subsection{Reliability Test}

The Cronbach's alpha values are presented in the table below (Table 3) with demographic indicators (0.739); psychographic indicators (0.776); economic indicators (0.755); socio-cultural indicators (0.731). Thus, variables in this study are reliable and can be used for quantitative analysis as the Cronbach's alpha is at least 0.70 or higher.

Table 1. Correlation analysis.

\begin{tabular}{ccccc}
\hline Variables & $\begin{array}{c}\text { Customer } \\
\text { Satisfaction }\end{array}$ & $\begin{array}{c}\text { Psychographic } \\
\text { Indicators }\end{array}$ & $\begin{array}{c}\text { Economic } \\
\text { Indicators }\end{array}$ & $\begin{array}{c}\text { Socio-cultural } \\
\text { Indicators }\end{array}$ \\
\hline Customer Satisfaction & 1 & & \\
Psychographic Indicators & $0.633^{* *}$ & 1 & 1 \\
Economic Indicators & $0.628^{* *}$ & $0.637^{\star *}$ & $0.669^{* *}$ & 1 \\
Socio-Cultural Indicators & $0.556^{* *}$ & $0.545^{* *}$ & & 1 \\
\hline
\end{tabular}

**. Correlation is significant at the 0.01 level (2-tailed).

Table 2. Measures of association.

\begin{tabular}{ccc}
\hline & Eta & Eta squared (h2) \\
\hline Psychographic Indicators * Customer Satisfaction & 0.594 & 0.352 \\
Economic Indicators * Customer Satisfaction & 0.584 & 0.341 \\
Socio-cultural Indicators * Customer Satisfaction & 0.674 & 0.455
\end{tabular}

Table 3. Reliability test.

\begin{tabular}{cccc}
\hline Variables & No of Item & Cronbach's alpha & $\begin{array}{c}\text { Cronbach's alpha } \\
\text { standardized items }\end{array}$ \\
\hline Customer Satisfaction & 1 & 0.728 & 0.701 \\
Demographic Indicators & 7 & 0.739 & 0.707 \\
Psychographic Indicators & 11 & 0.776 & 0.754 \\
Economic Indicators & 2 & 0.755 & 0.748 \\
Social Indicators & 3 & 0.731 & 0.711
\end{tabular}




\subsection{Normality Test}

The results of the normality test for psychographic indicators, economic indicators, and socio-economic indicators indicated that all significance values (Sig.) were less than 0.05. This was Spearman's Rank Order Correlation and also a nonparametric measure of the strength and direction of the association.

The above table (Table 4) presents the results from two well-known tests of normality, namely the Kolmogorov-Smirnov Test and the Shapiro-Wilk Test. The Shapiro-Wilk Test is more appropriate for small sample sizes ( $<50$ samples), but can also handle sample sizes as large as 2000 . For this reason, we will use the Shapiro-Wilk test as our numerical means of assessing normality.

We can see from the above table that for the "Demographic Indicators", "Psychographic Indicators", "Economic Indicators" and "Socio-cultural Indicators" Group the dependent variable, "Customer Satisfaction", was normally distributed as the p-value were above 0.05 .

\subsection{Ethics Statement}

The formal ethical approval of this research was received from the relevant agency and the research adhered to the Helsinki Declaration as updated in Fortaleza. Before their inclusion in this research, permission was received from respondents and their privacy was assured. Before continuing to the questionnaire, all the participants were told about the particular purpose of this analysis. Participants were only able to complete the survey once and were able to end the survey at any moment they chose. Anonymity and secrecy of the information were guaranteed. The competent authority has received formal ethical clearance for this report.

\section{Conceptual Framework}

This conceptual framework was designed by reviewing different theories that affected consumers' buying pattern and explained their dependency on e-commerce. Theory of Reasoned Action (Vallerand et al., 1992) was one of the most relevant theories that emphasized on psychographic factors; more precisely attitude or perception of consumers how their purchasing decision was controlled by issues like perception towards the product and services, its value, security, cost-effectiveness etc.

Table 4. Tests of normality.

\begin{tabular}{ccccccc}
\hline & \multicolumn{3}{c}{ Kolmogorov-Smirnov } & \multicolumn{3}{c}{ Shapiro-Wilk } \\
\cline { 2 - 7 } & Statistic & df & Sig. & Statistic & df & Sig. \\
\hline Demographic Factors & 0.367 & 220 & 0.219 & 0.685 & 220 & 0.174 \\
Psychographic Indicators & 0.327 & 220 & 0.310 & 0.745 & 220 & 0.259 \\
Economic Indicators & 0.245 & 220 & 0.215 & 0.825 & 220 & 0.712 \\
Socio-cultural Indicators & 0.358 & 220 & 0.625 & 0.698 & 220 & 0.253 \\
\hline
\end{tabular}

b. Lilliefors Significance Correction. 
Many principles in economics also triggered consumers' income as an influential factor in consumers' behaviour that made a great change in consumers' intention to adopt e-commerce as their means of purchasing (Putra et al., 2017). The principle showed a proportionate relation between consumers' income and rate of consumption. Hence, it resulted in an affluent change in consumers' lifestyle. Demographic factors like age, occupation, family size also had an impact on consumers' mind to replace traditional purchasing behaviour (Kacen \& Lee, 2002; Muniady et al., 2014). All the factors were segmented into demographic, psychographic, economic and socio-economic variables on which customers' behaviour was dependent and could explain the relationships among them (Figure 1).

\section{Data Analysis and Study Findings}

\subsection{Demographic Characteristics of the Respondents}

The bellow table (Table 5) shows that among the 220 respondents, 141 (64.1\%) were male, with the proportion marginally higher than female respondents, which is equal to 79 (35.9\%). Most of these respondents (84.5\%) were between 31 to 40 years of age. There are 163 respondents (74.1\%) were married. Besides, there were 151 respondents (68.6\%) from private occupation. 92 respondents (41.8\%) were in the income range of 26 - 50 thousand and most of the respondents' (37.3\%) monthly expenditure was in the range of $35-45$ thousand. The majority of the respondents (65.5\%) had the family size of 3 - 4 members. Respondents of this study were from private sectors between an age range of 31 years to 40 years could be the most prominent for using the e-commerce and a family with members of 3 - 4 whereas the married persons mostly demanded online service. People within mid-range to high income are potential to use e-commerce (Z. Hossian, personal communication, May 22, 2019).

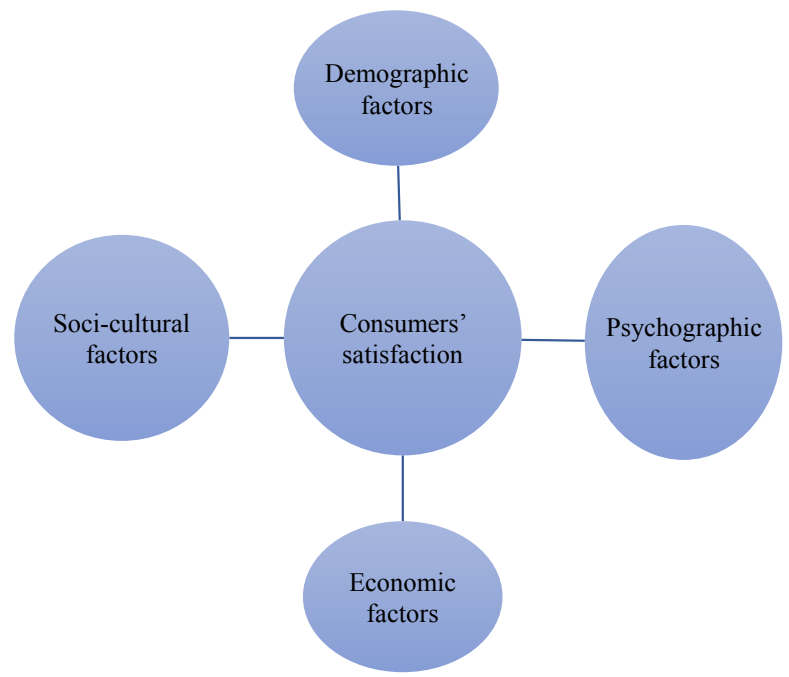

Figure 1. Conceptual Framework. (Sources: Vallerand et al., 1992; Putra, Said and Hasan, 2017; Kacen and Lee, 2002). 
Table 5. Demographic information of the respondents.

\begin{tabular}{|c|c|c|c|}
\hline Variables & Criteria & Frequency (n) & Percentage (\%) \\
\hline \multirow{3}{*}{ Age } & $21-30$ & 23 & 10.5 \\
\hline & $31-40$ & 186 & 84.5 \\
\hline & $41-50$ & 11 & 5.0 \\
\hline \multirow{2}{*}{ Gender } & Male & 141 & 64.1 \\
\hline & Female & 79 & 35.9 \\
\hline \multirow{2}{*}{ Marital Status } & Married & 163 & 74.1 \\
\hline & Unmarried & 57 & 25.9 \\
\hline \multirow{5}{*}{ Occupation } & Govt. Job & 8 & 3.6 \\
\hline & Pvt. Job & 151 & 68.6 \\
\hline & Business & 40 & 18.2 \\
\hline & Unemployed & 5 & 2.3 \\
\hline & Others & 16 & 7.3 \\
\hline \multirow{6}{*}{ Monthly Income (In Thousand) } & $0-25$ & 19 & 8.6 \\
\hline & $26-50$ & 92 & 41.8 \\
\hline & $51-75$ & 61 & 27.7 \\
\hline & $61-75$ & 17 & 7.7 \\
\hline & $76-100$ & 25 & 11.4 \\
\hline & More than 100 & 6 & 2.7 \\
\hline \multirow{5}{*}{ Monthly Expenditure (In Thousand) } & Below 20 & 25 & 11.4 \\
\hline & $20-35$ & 34 & 15.5 \\
\hline & $35-45$ & 82 & 37.3 \\
\hline & $45-60$ & 52 & 23.6 \\
\hline & 60 -above & 27 & 12.3 \\
\hline \multirow{3}{*}{ Family Size } & $1-2$ & 34 & 15.5 \\
\hline & $3-4$ & 144 & 65.5 \\
\hline & $5+$ & 42 & 19.1 \\
\hline
\end{tabular}

\subsection{Influencing Factors of Consumer Satisfaction: A Multiple Regression Analysis}

This research used the multiple regression model to evaluate how Demographic indicators, Psychographic indicators, Economic indicators and Socio-Cultural indicators which influences e-commerce customer satisfaction. The $r_{2}$ value, as shown in the table below (Table 6), specifies the sum of the variation (variance) described in customer satisfaction towards e-commerce (dependent variable) from the three variables within a range of $0 \%$ to $100 \%$. The analysis can thus claim that $62.1 \%$ of the variance in consumer satisfaction is accounted for by the combined linear impact of the predictor variables, i.e., demographic, psycho- 
graphic; economic; and socio-cultural indicators.

It is noted that the total variance is partitioned into the variance that can be explained by the independent variables (regression) and the variance but this cannot be explained by the independent variables (residual). From the bellow table (Table 7), the sum of squares is the total variance (296.232), which included regression (181.474) and residual (114.758). The p-value for the $F$ test is 0.000 , which was less than the chosen $5 \%$ level of significance and also indicated a good model fit. Apart from this it also indicated that the independent variables such as Demographics; Psychographic; Economic; and Socio-cultural indicators can be used to predict customer satisfaction towards e-commerce.

Findings in below table (Table 8) indicated that Psychographic indicators; Economic indicators; and Socio-cultural indicators were significant factors in contributing to customer satisfaction towards e-commerce, as the p-value was less than the chosen 5\% level of significance. Psychographic Indicators; Economic Indicators; and Socio-cultural Indicators coefficients $(0.049,0.339$ and 0.297 respectively) were positive, indicated a positive effect of Psychographic Indicators; Economic Indicators; and Socio-cultural Indicators coefficients on customer satisfaction towards e-commerce. However, the demographic factor is not statistically significant (0.321) and do not put any impact on customer satisfaction.

Table 6. ANOVA analysis.

\begin{tabular}{ccccc}
\hline Model & R & R Square & Adjusted R Square & Std. Error of the Estimate \\
\hline 1 & 0.701 & 0.621 & 0.597 & 0.627 \\
\hline
\end{tabular}

Table 7. Analysis of variance.

\begin{tabular}{cccccc}
\hline Model & Sum of Squares & Df & Mean Square & F & Sig. \\
\hline Regression & 181.474 & 5 & 36.295 & 67.682 & 0.000 \\
Residual & 114.758 & 214 & 0.536 & & \\
Total & 296.232 & 219 & & & \\
\hline
\end{tabular}

Table 8. Unstandardized coefficients.

\begin{tabular}{|c|c|c|c|c|c|}
\hline \multirow[t]{2}{*}{ Model } & \multicolumn{3}{|c|}{$\begin{array}{l}\text { Unstandardized } \\
\text { Coefficients }\end{array}$} & \multirow[t]{2}{*}{$\mathrm{T}$} & \multirow[t]{2}{*}{ Sig. } \\
\hline & B & Std. Error & Beta & & \\
\hline (Constant) & 0.990 & 0.254 & & 3.896 & 0.000 \\
\hline Demographic Factor & 0.321 & 0.179 & 0.216 & 1.216 & 0.562 \\
\hline Psychographic Factors & 0.049 & 0.058 & 0.040 & 0.762 & 0.000 \\
\hline Economic Factors & 0.339 & 0.062 & 0.205 & 3.371 & 0.000 \\
\hline Socio-cultural Factors & 0.297 & 0.067 & 0.927 & 1.643 & 0.003 \\
\hline
\end{tabular}




\section{Discussion}

Gender was a great concern of this study as both male and female were the research sample of this study. The previous study found that gender is a key component in internet-based technology adoption (Bagchi, 2005). Among the 220 research respondent vast proportion were young and their age around 31 to 40 years old. Several research papers on the emergence of innovations have found that age is a significant factor in the acceptance of innovation (Comin \& Hohijn, 2004). Economic condition plays important role in e-commerce business. Of the research sample $41.8 \%$, are in the income range of $26-50$ thousand and the monthly expenditure for most of the respondents (37.3\%) is in the range of 35 45 thousand. The study also found that implementers of internet-based innovation belong to high-income groups (Siyal et al., 2006).

This study emphasized on some variables, like customer satisfaction, psychographic indicators, economic condition and socio-economic condition of the respondent. The study found that there was an association between Customer Satisfaction and Psychographic Indicators. The correlation coefficient between Customer Satisfaction and Psychographic Indicators was a positive value because when Customer Satisfaction increases, the Psychographic Indicators also increases. The study also found that the correlation coefficient was a positive value between Customer Satisfaction and economic indicator. The finding of other variables was that there was an association between Psychographic Indicators and Socio-Economic Indicators.

The correlation coefficient also had a positive value like other factors of this study. Besides, many studies in this field have found that there are systematic variations prevail in customer loyalty and satisfaction between online and offline retail environment (Cao \& Li, 2015; Ansari et al., 2008; Ailawadi \& Farris, 2017). Consumers become satisfied when they can fulfill their desires and wants (Oliver, 1993). Major findings of this study were that because of a busy lifestyle, people now look for an easy way to get their job done and willing to spend to get the quality and hassle-free service. Service providers have good ability in their job that ensures quality service which agreed with a decent number of customers and that leads to customer satisfaction. It is also known that selling goods and services online is less expensive than the conventional way of doing business. Furthermore, quality in e-commerce has been the main challenge for online retailers if they want to succeed because of strong competition and more quality-wise demands from consumers.

The research showed Sheba.xyz was able to gain the trust from a large part of its customers and that was why most of the respondents had the interest to take service from it again. More than $80 \%$ of Sheba.xyz users agreed that income and e-commerce brought a change in living standard and wanted such online platforms more. Most of the work in this area had shown that there were systemic variations between online and offline consumer service shopping environments (Rahman et al., 2020; Cao \& Li, 2015; Ailawadi \& Farris, 2017). The happiness of 
the customer was the response of the user (Oliver, 1993).

The response rate for the survey was not adequate, making it hard to generalize the outcome of this report, despite attempts were made to spread the survey broadly through social media channels. The majority of participants who had access to a smartphone were more likely to participate, which was a limitation for the study. Though, because of the current pandemic situation during the time of data collection, the online survey was the feasible option for performing the survey. And, from this point of view, the study could not collect the opinion of individuals from different strata of the country. Further research could investigate alternative methods of collecting more participants with adequate time from different part of the country.

\section{Conclusion}

This study concluded that the use of e-commerce was growing rapidly with the advancement of technology. The ability of consumers to purchase through the internet worked as replacements for conventional ways of shopping. It was also the research's key motivator. The outcome provided a partial description and impacts of the e-commerce market in the way it draws its clients. The first move for professionals was to create an internet marketplace for shoppers, but more critically, to convince consumers to utilize the online shopping site. In Bangladesh, if the influence of culture prevails as predicted, marketers need to take proper steps to reduce the perceived risk of shopping online. Although consumer self-efficacy and enabling conditions have played a major role in deciding the desire of consumers to pursue online shopping in the past decade, provided that consumers are now acquainted with the internet today, they need to be persuaded of sufficient protection measures. This should gain trust, and raise the perceived danger of shopping online.

Likewise, the increase in Bangladesh's dual-income households shows that customers are under time strain, and the Clichés would be key in embracing online shopping. When more consumers continue buying digitally, the winning card to draw non-internet retail clients would be a good appraisal of their experience. There is the scope for further research on this site where sample size can be increased and rural populace can be added to reflect the total picture of different levels of consumers in Bangladesh and their online purchasing behaviour. Research can also be done to look for other aspects that could stimulate online shopping behaviour by developing customer satisfaction and building customer loyalty. Besides, future research can be done for the decision-makers to think about different attributes to include in the products and service, such as quality assurance, method of delivery, payment access system, security facts, reliability, and pricing policy.

\section{Authors Contributions}

$\mathrm{TH}$ wrote the draft, completed the writing and edited the draft, TA supervised 
the project, DMNA collected the data, KFZ analyzed the data and SSA wrote methodology and AR wrote the discussion. All authors have read and agreed to the published version of the manuscript.

\section{Declarations}

\section{Funding}

Self-funding by the authors (information that explains whether and by whom the research was supported).

\section{Availability of Data and Material}

Data will be available if required.

\section{Consent to Participate}

Due consent was taken from the participant.

\section{Conflicts of Interest}

The authors declare no conflicts of interest regarding the publication of this paper.

\section{References}

Abir, T., Rahman, M. A., Yazdani, D. M. N., Khan, R. H., Supty, S. S. A., \& Hamid, A. B. A. (2020). Electronic Word of Mouth (e-WOM) and Consumers' Purchase Decision: Evidences from Bangladesh. Journal of Xi' an University of Architecture \& Technology, $12,367-382$.

Ailawadi, K. L., \& Farris, P. W. (2017). Managing Multi- and Omni-Channel Distribution: Metrics and Research Directions. Journal of Retailing, 93, 120-135. https://doi.org/10.1016/j.jretai.2016.12.003

Ansari, A., Mela, C. F., \& Neslin, S. A. (2008). Customer Channel Migration. Journal of Marketing Research, 45, 60-76. https://doi.org/10.1509/jmkr.45.1.60

Bagchi, K. (2005). Factors Contributing to Global Digital Divide: Some Empirical Results. Journal of Global Information Technology Management, 8, 47-65. https://doi.org/10.1080/1097198X.2005.10856402

BTRC (2020). Mobile Phone Subscribers in Bangladesh January, 2020. BTRC, Bangladesh Telecommunication Regulatory Commission. http://www.btrc.gov.bd/content/mobile-phone-subscribers-bangladesh-january-2020

Cao, L., \& Li, L. (2015). The Impact of Cross-Channel Integration on Retailers' Sales Growth. Journal of Retailing, 91, 198-216. https://doi.org/10.1016/j.jretai.2014.12.005

Chan, J. (2017). Digital Connectivity as the Next ASEAN Dream. ASEAN Today. https://www.aseantoday.com/2017/12/digital-connectivity-as-the-next-asean-dream

Comin, D., \& Hobijn, B. (2004). Cross-Country Technology Adoption: Making the Theories Face the Facts. Journal of Monetary Economics, 51, 39-83. https://doi.org/10.1016/j.jmoneco.2003.07.003

Dan, C. (2014). Electronic Commerce: State-of-the-Art. American Journal of Intelligent Systems, 4, 135-141. 
Dey, S. K., Nabi, M. N., \& Anwer, M. (2009). Challenges in Building Trust in B2C E-Commerce and Proposal to Mitigate Them: Developing Countries Perspective. 2009 12th International Conference on Computers and Information Technology, Chengdu, 27-29 October 2009, 581-586.

Dholakia, R. R., \& Chiang, K. P. (2003). Shoppers in Cyberspace: Are They from Venus or Mars and Does It Matter? Journal of Consumer Psychology, 13, 171-176. https://doi.org/10.1207/S15327663JCP13-1\&2_15

Erasmus, A. C., Boshoff, E., \& Rousseau, G. G. (2001). Consumer Decision-Making Models within the Discipline of Consumer Science: A Critical Approach. Journal of Family Ecology and Consumer Sciences, 29, 82-90. https://doi.org/10.4314/jfecs.v29i1.52799

Hassan, S. M. (2014). History of E-Commerce in Bangladesh.

Jamil, M. R., \& Ahmad, N. (2009). Present Status and Critical Success Factors of e-Commerce in Bangladesh. 2009 12th International Conference on Computers and Information Technology, Chengdu, 27-29 October 2009, 632-637. https://doi.org/10.1109/ICCIT.2009.5407313

Kacen, J. J., \& Lee, J. A. (2002). The Influence of Culture on Consumer Impulsive Buying Behavior. Journal of Consumer Psychology, 12, 163-176. https://doi.org/10.1207/S15327663JCP1202_08

Karim, M. T., \& Qi, X. (2018). E-Commerce Development in Bangladesh. International Business Research, 11, 201-211. https://doi.org/10.5539/ibr.v11n11p201

Koyuncu, C., \& Bhattacharya, G. (2004). The Impacts of Quickness, Price, Payment Risk, and Delivery Issues on On-Line Shopping. The Journal of Socio-Economics, 33, 241-251. https://doi.org/10.1016/j.socec.2003.12.011

Laisuzzaman, I. M., Imran, N., Nahid, A. A., Ziaul, M., \& Alim, M. (2010). The Framework for Implementing Ecommerce: The Role of Bank and Telecom in Bangladesh.

Limayem, M., Khalifa, M., \& Frini, A. (2000). What Makes Consumers Buy from Internet? A Longitudinal Study of Online Shopping. IEEE Transactions on Systems, Man, and Cybernetics Part A: Systems and Humans, 30, 421-432. https://doi.org/10.1109/3468.852436

Lin, A. C. H. (2015). Facilitating Cultural and Creative Industries to Engage the Internet Era: A New E-Commerce Strategic Framework. American Journal of Economics, 5, 534-539.

Lucking-Reiley, D., \& Spulber, D. F. (2001). Business-to-Business Electronic Commerce. Journal of Economic Perspectives, 15, 55-68. https://doi.org/10.1257/jep.15.1.55

Mohiuddin, M. (2014). Overview the E-Commerce in Bangladesh. IOSR Journal of Business and Management, 16, 1-6. https://doi.org/10.9790/487X-16720106

Muniady, R., Al-Mamun, A., Permarupan, P. Y., \& Zainol, N. R. B. (2014). Factors Influencing Consumer Behavior: A Study among University Students in Malaysia. Asian Social Science, 10, 18. https://doi.org/10.5539/ass.v10n9p18

Niranjanamurthy, M., Kavyashree, N., Jagannath, S., \& Chahar, D. (2013). Analysis of E-Commerce and M-Commerce: Advantages, Limitations and Security Issues. International Journal of Advanced Research in Computer and Communication Engineering, 2, 2360-2370.

Oliver, R. L. (1993). Cognitive, Affective, and Attribute Bases of the Satisfaction Response. Journal of Consumer Research, 20, 418-430. https://doi.org/10.1086/209358

Parvin, I., Azim, A., \& Sultana, F. N. (2007). Information Communication Technology in Rural Development of Bangladesh. The Journal of Rural Development, 35, 61-88. 
Putra, A. H. P. K., Said, S., \& Hasan, S. (2017). Implication of External and Internal Factors of Mall Consumers in Indonesia to Impulsive Buying Behavior. International Journal of Business Accounting and Management, 2, 1-10.

Rahman, M. A., Abir, T., Yazdani, D. M. N., Hamid, A. B. A., \& Al Mamun, A. (2020). Brand Image, eWOM, Trust and Online Purchase Intention of Digital Products among Malaysian Consumers. Journal of Xi'an University of Architecture \& Technology, 12, 4935-4946.

Rahman, M. A., Khan, S. A., Hamid, A. B. A., Latiff, A. S. A., \& Mahmood, R. (2018). Impact of Electronic Word of Mouth (e-WOM) on Brand Image and Online Purchase Intention: The Perspective of Bangladesh. Proceedings of 3rd International Conference on Dynamic Innovation, Langkawi, 2018, 61-79. https://doi.org/10.2139/ssrn.3490628

Rowley, J. (2001). Remodelling Marketing Communications in an Internet Environment. Internet Research, 11, 203-212. https://doi.org/10.1108/10662240110397017

Schlesselman, J. J. (1974). Sample Size Requirements in Cohort and Case-Control Studies of Disease. American Journal of Epidemiology, 99, 381-384. https://doi.org/10.1093/oxfordjournals.aje.a121625

Shankar, V., Smith, A. K., \& Rangaswamy, A. (2003). Customer Satisfaction and Loyalty in Online and Offline Environments. International Journal of Research in Marketing, 20, 153-175. https://doi.org/10.1016/S0167-8116(03)00016-8

Sheba.xyz (2016). About Sheba.xyz. Sheba Blog. https://www.sheba.xyz/blog/bn/about

Siyal, M. Y., Chowdhry, B. S., \& Rajput, A. Q. (2006). Socio-Economic Factors and Their Influence on the Adoption of E-Commerce by Consumers in Singapore. International Journal of Information Technology \& Decision Making, 5, 317-329. https://doi.org/10.1142/S021962200600199X

Sohrabi, C., Alsafi, Z., O’Neill, N., Khan, M., Kerwan, A., Al-Jabir, A., Agha, R. et al. (2020). World Health Organization Declares Global Emergency: A Review of the 2019 Novel Coronavirus (COVID-19). International Journal of Surgery, 76, 71-76. https://doi.org/10.1016/j.ijsu.2020.02.034

Swinyard, W. R., \& Smith, S. M. (2003). Why People (Don't) Shop Online: A Lifestyle Study of the Internet Consumer. Psychology \& Marketing, 20, 567-597. https://doi.org/10.1002/mar.10087

The Economic Times (2020). Bangladesh Is about to Beat India in Regional per Capita GDP Sweepstakes.

The Financial Express (2019). Growth Strategy Needs to Focus on Human Development. https://thefinancialexpress.com.bd/views/growth-strategy-needs-to-focus-on-human-d evelopment-1566402675

Vallerand, R. J., Deshaies, P., Cuerrier, J. P., Pelletier, L. G., \& Mongeau, C. (1992). Ajzen and Fishbein's Theory of Reasoned Action as Applied to Moral Behavior: A Confirmatory Analysis. Journal of Personality and Social Psychology, 62, 98. https://doi.org/10.1037/0022-3514.62.1.98

Von Ahn, L., Blum, M., \& Langford, J. (2004). Telling Humans and Computers Apart Automatically. Communications of the ACM, 47, 56-60. https://doi.org/10.1145/966389.966390

Worldometer (2020). Bangladesh Population (2020). Worldometer-Real Time World Statistics. https://www.worldometers.info/world-population/bangladesh-population 